\title{
SOSIALISASI PENGGUNAAN INTERNET SEHAT DI SMK NEGERI 1 MARISA KABUPATEN POHUWATO
}

\section{SOCIALIZATION OF HEALTHY INTERNET USE IN VOCATIONAL SCHOOL 1 MARISA POHUWATO DISTRICT}

\author{
Ruly S. Sinukun ${ }^{1}$ ), Roys Pakaya ${ }^{2)}$, Abdul Rahman Tapate ${ }^{3)}$ \\ $1,{ }^{2},{ }^{3}$ ) Staf Pengajar Program Studi Teknik Informatika, Politeknik Gorontalo \\ J1. Muchlis Rahim Desa Panggulo, Kec. Botupingge, Kab. Bone Bolango, Prov. Gorontalo \\ Email : rulysinukun@ poligon.ac.id
}

\begin{abstract}
ABSTRAK
Internet sebagai pusat pencarian dan penyediaan data sangat bermanfaat bagi para siswa untuk proses pembelajaran. Namun, kurangnya kesadaran akan penggunaan internet yang sehat menyebabkan tidak dapat dihindarinya dampak negatif dari internet. Begitu pula halnya dengan siswa-siswi yang berada di SMK Negeri 1 Marisa Kabupaten Pohuwato. Untuk menghindari penggunaan internet yang berlebihan, tidak terkontrol, dan tidak benar, Sosialisasi Penggunaan Internet Sehat menjadi sangat penting untuk dilaksanakan. Dalam sosialisasi ini juga disampaikan Undang-Undang Informasi dan Transaksi Elektronik (Undang-Undang No. 11 tahun 2008). Kegiatan sosialisasi ini bertujuan untuk menambah pengetahuan para siswa-siswi di SMK Negeri 1 Marisa Kabupaten Pohuwato. Adapun hasil dari pengabdian ini adalah pertama, adanya kesadaran pihak sekolah akan pentingnya upaya terus melakukan kontrol terhadap penggunaan Internet oleh siswa agar mereka menjadi pribadi yang berhasil di masa depan. Kedua, pengabdian ini telah meningkatkan pengetahuan ataupun pemahaman siswasiswi SMK Negeri 1 Marisa Kabupaten Pohuwato tentang norma-norma dan dampak yang ditimbulkan dalam menggunakan internet, sehingga para siswa-siswi lebih bijaksana di dalam menggunakan teknologi internet. Hal ini nampak dari begitu antusiasnya para siswa dalam sesi diskusi. Ketiga, terjalinnya kerjasama antara kampus dan sekolah. Kegiatan pengabdian ini diharapkan dapat menjadi salah satu upaya pendampingan penggunaan internet sehat di lingkungan sekolah menengah atas atau yang setara.
\end{abstract}

Kata Kunci: Sosialisasi, Internet, Sehat

\begin{abstract}
The internet as a center for searching and providing data is very useful for students for the learning process. However, the lack of awareness of the use of a healthy internet can not avoid the negative effects of the internet. The same is true for students who are in SMK Negeri 1 Marisa, Pohuwato Regency. To avoid excessive, uncontrolled, and incorrect internet use, the Socialization of Healthy Internet Usage is very important to be carried out. In this socialization the Information and Electronic Transaction Law (Law No. 11 of 2008) was also conveyed. This socialization activity aims to increase the knowledge of the students at SMK Negeri 1 Marisa, Pohuwato Regency. The results of this service are first, there is awareness of the school of the importance of continuing efforts to control the use of the Internet by students so that they become successful individuals in the future. Secondly, this dedication has increased the knowledge or understanding of students of SMK Negeri 1 Marisa Pohuwato Regency about the norms and impacts caused in using the internet, so that students are wiser in using internet technology. This can be seen from the enthusiasm of the students in the discussion session. Third, the establishment of cooperation between campus and school. This community service is expected to be one of the efforts to assist the use of a healthy internet in high school or equivalent.
\end{abstract}

Keywords: Socialization, Internet, Healthy 


\section{PENDAHULUAN}

Internet merupakan inovasi modern berupa jaringan komunikasi global yang menjanjikan berbagai kemudahan dalam komunikasi, transfer data, akses hiburan lentertainment, bahkan transaksi keuangan maupun bisnis. Kemudahan itu berupa kecepatan, keluwesan, efisiensi waktu, biaya dan tenaga (Nurul Iman, dkk, 2014). Tidak hanya terbatas pada kalangan tertentu, kepraktisan dan kemudahan yang didapatkan dari penggunaan internet juga turut dirasakan oleh para pendidik dan peserta didik di sekolah.

Disediakannya akses internet di sekolah tentu akan mempermudah siswa-siswi dalam memperoleh layanan internet dan sudah semestinya dibarengi dengan sosialiasi berinternet secara sehat dan bijak. Namun demikian, internet bagaikan pisau bermata dua. Selain dampak positif juga ada dampak negatif yang mengancam para siswa secara khusus. Kurangnya pengetahuan siswa-siswi akan penggunaan internet yang sehat, dapat merugikan dan menimbulkan dampak negatif bagi kehidupan dan kelangsungan generasi penerus bangsa.

Tidak adanya edukasi akan penggunaan internet yang sehat menyebabkan tidak dapat dihindarinya dampak negatif dari internet. Oleh karena itu terhadap para siswa khususnya di kalangan sekolah menengah/kejuruan sangat penting untuk terus dibina agar muncul kesadaran kolektif akan pentingnya menggunakan internet secara sehat dan bijaksana, sehingga mereka mampu mendapatkan manfaat positif dari penggunaan internet.

Edukasi ini diperlukan terutama bagi kalangan siswa yang tergolong masih labil atau yang baru melek internet guna menghindari kasus-kasus yang tidak diinginkan, seperti: pelanggaran UU ITE (Rini Agustina, 2016) penyalahgunaan internet, dan dampak social internet.

Internet Sehat dan Aman (INSAN) adalah suatu program dari pemerintah Indonesia yang dicanangkan oleh Kementerian Komunikasi dan Informatika Indonesia (Kemkominfo) dengan tujuan untuk mensosialisasikan penggunaan internet secara sehat dan aman melalui pembelajaran etika berinternet secara sehat dengan melibatkan seluruh komponen masyarakat.

Penggunaan internet yang tidak terkontrol akan menyebabkan banyak kerugian. Penggunaan internet oleh siswa-siswi yang tidak terkontrol oleh guru akan memberi efek buruk pada kehidupan sosial dan psikologis para siswa, bahkan akademik mereka. Dan untuk menghindari penggunaan internet yang berlebihan, tidak terkontrol, dan tidak benar, dibutuhkan peran pendidik untuk terus memberikan penyadaran atau mensosialisasikan penggunaan internet secara benar kepada para siswa-siswi.

Berdasarkan kondisi di atas, sangat berbahaya jika internet digunakan dengan salah oleh kalangan siswa-siswi. Oleh karena itu tim pengabdian Prodi TI Poligon akan mengadakan Sosialisasi Penggunaan Internet Sehat untuk meningkatkan pengetahuan siswa-siswa terutama pada sekolah-sekolah yang berlokasi jauh dari pusat kota. Kegiatan ini akan dilaksanakan di SMK Negeri 1 Marisa, Kabupaten Pohuwato. SMK Negeri 1 Marisa merupakan sekolah kejuruan negeri yang berada di desa Teratai kecamatan Marisa Kabupaten Pohuwato Provinsi Gorontalo.

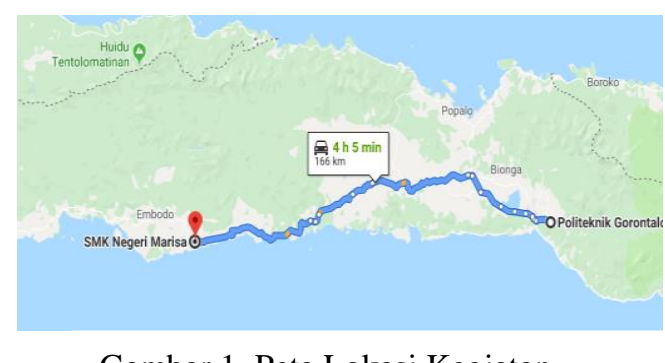

Gambar 1. Peta Lokasi Kegiatan

Sosialisasi penggunaan internet sehat ini sebagai bentuk implementasi salah satu Tri Dharma Perguruan Tinggi yaitu pengabdian terhadap masyarakat. Kegiatan pengabdian ini, diharapkan dapat meningkatkan pengetahuan para siswa-siswi SMK Negeri 1 Marisa Kabupaten Pohuwato serta mampu memanfaatkan internet secara optimal, secara sehat dan bijaksana.

\section{Permasalahan Mitra}

Internet sehat adalah upaya pemanfaatan teknologi informasi (IT) yang bebas dari pornografi maupun pornoaksi, di dalam banyak kasus, para siswa sekolah menengah lebih mampu menggunakan dan memanfaatkan fasilitas internet daripada para guru, meskipun 
digunakan hanya untuk kesenangan saja bukan dalam kerangka akademik. Adalah suatu hal yang umum terjadi, generasi muda lebih mudah dalam mengikuti perkembangan teknologi. Oleh karenanya, menjadi tugas para pendidik untuk memberikan arahan kepada para siswanya dalam memanfaatkan internet. Karena internet pun mempunyai dampak negatif bagi penggunanya karena adanya situssitus yang menyajikan hal-hal yang tidak bermoral dan bertentangan dengan ajaran agama.

Bahaya Internet yang agak sulit dihindari adalah konten negatif. Masalah lainnya, terkadang siswa-siswi mengakses konten negatif bukan karena mereka tertarik, melainkan terpapar secara tidak sengaja walaupun tak dapat dipungkiri ada sengaja melakukannya . Misalnya, ketika ada siswa yang googling pelajaran SMK. Di hasil pencarian, malah muncul konten negatif. Pada dasarnya siswa-siswi sebetulnya tidak mencari konten negatif, tetapi mungkin pada saat mereka melakukan pencarian, konten negatif itulah yang muncul. Artinya, kita tidak bisa dengan mudahnya melakukan pelarangan atau pemblokiran.

Kurangnya kesadaran siswa tentang dampak positif dan negatif dalam penggunaan internet di kalangan siswa SMK yang menjadi dasar atau urgensi pentingnya pengabdian ini dilakukan. Dengan adanya sosialisasi ini diharapkan siswa-siswi SMK Negeri 1 Marisa Kabupaten Pohuwato, menjadi lebih mengerti manfaat dari Internet dan juga sisi negatifnya, serta dapat mengembangkan potensi melalui Internet.

\section{SOLUSI DAN TARGET LUARAN}

\section{Solusi Permasalahan}

Banyaknya kasus-kasus penggunaan internet yang tidak benar dan mampu berdampak negatif membangkitkan rasa prihatin di kalangan dosen Teknik Informatika. Salah satu segmen yang sudah banyak menggunakan internet adalah siswa-siswi sekolah kejuruan (SMKN 1 Marisa). Olehnya, sosialisasi penggunaan internet sehat sangat penting dan menjadi keharusan, mengingat kalangan remaja adalah masa-masa emas pertumbuhan manusia. Hal ini perlu dilakukan agar para siswa-siswi SMK mampu memanfaaatkan internet secara bijak dan optimal.

\section{Luaran dan Target Capaian}

Luaran yang diharapkan dari kegiatan ini adalah :

1. Mewujudkan kesadaran pihak sekolah akan pentingnya upaya pembinaan penggunaan internet secara bijaksana dikalangan siswa.

2. Meningkatnya pengetahuan siswa siswa dalam memanfaatkan internet secara optimal, secara sehat dan bijaksana.

3. Terjalinnya kerjasama antara kampus dan sekolah.

\section{METODE PELAKSANAAN}

Metode yang digunakan dalam pelaksanaan kegiatan Pengabdian Kepada Masyarakat ini adalah metode audiensi dan ceramah. Kegiatan pengabdian ini diawali dengan audiensi antara tim pelaksana dan mitra atau pihak sekolah SMK Negeri 1 marisa Kabupaten Pohuwato. Audiensi dilakukan untuk menjalin hubungan yang baik antara pelaksana pengabdian dan pihak sekolah SMK Negeri 1 Marisa. Dalam kegiatan audiensi ini tim pelaksana TI Poligon akan menyampaikan seluruh program yang akan dilaksanakan, peranan pelaksana dan mitra dalam kegiatan ini. Selanjutnya, dalam sosialisasi menggunakan metode ceramah. Penjelasan materi ceramah oleh narasumber menggunakan bantuan LCD Proyektor dan menggunakan aplikasi power point. Penjelasan teknik-teknik dan cara penanggulangan dengan menggunakan komputer dan smartphone.

Tabel 1 Tema Materi dan Pemateri

\begin{tabular}{|c|l|c|}
\hline No & \multicolumn{1}{|c|}{ Tema Materi } & Pemateri \\
\hline \multirow{2}{*}{1} & $\begin{array}{l}\text { Internet Sehat dan } \\
\text { Contoh-contoh } \\
\text { Aplikasinya }\end{array}$ & $\begin{array}{c}\text { Ruly S. } \\
\text { Sinukun, } \\
\text { S.Kom., M.T }\end{array}$ \\
\hline \multirow{2}{*}{2} & $\begin{array}{l}\text { Internet } \\
\text { (penyalagunaan } \\
\text { dan dampak } \\
\text { hukum) }\end{array}$ & $\begin{array}{c}\text { Roys Pakaya, } \\
\text { S.Kom., M.Kom }\end{array}$ \\
\hline 3 & $\begin{array}{l}\text { Internet dalam } \\
\text { pandangan Agama }\end{array}$ & $\begin{array}{c}\text { Abdul Rahman } \\
\text { Tapate, S.Pd.I., } \\
\text { M.Pd }\end{array}$ \\
\hline
\end{tabular}

Istilah internet sehat merupakan dua buah kata yang digabungkan untuk membentuk 
makna baru. Dalam KBBI (2001) Internet didefinisikan rangkaian komputer yang terhubung di dalam beberapa rangkaian. Internet sendiri berasal dari kata Interconnection Networking yang mempunyai arti hubungan berbagai komputer dengan berbagai tipe yang membentuk sistem jaringan yang mencakup seluruh dunia (jaringan komputer global) dengan melalui jalur komunikasi (Lina Aprilia, 2014). Jadi secara umum, internet merupakan jaringan yang dapat menghubungkan seluruh komputer di seluruh dunia.

Sedangkan sehat secara bahasa dapat diartikan dengan "baik seluruh badan dan bagian-bagiannya", "waras", "mendatangkan kebaikan pada badan", "sembuh dari sakit", dan "baik dan normal" (Redaksi, 2008). Menyebut internet sehat sesuai definisi tersebut sering dikaitkan dengan hal-hal yang bersifat fisik, konten materi dan sekaligus hal-hal yang bersifat perilaku. Berkenaan dengan pengabdian ini internet sehat yang dimaksud adalah internet yang dimanfaatkan secara optimal dan bijaksana.

Pada pengabdian ini, dampak positif internet dijabarkan menjadi beberapa hal :

a) Sebagai media informasi;

b) Sebagai media komunikasi;

c) sebagai media belajar dan hiburan;

d) Sebagai media transaksi

Pemanfaatan internet juga bisa memberikan dampak negatif, yaitu : a) berkurangnya sifat sosial, b) merubah pola interaksi sosial; c) kecenderungan berbuat kejahatan; d) kecanduan hal-hal negatif dari internet. e) memiliki konsekuensi hukum.

\section{Peralatan yang digunakan dalam kegiatan pengabdian}

Adapun peralatan yang digunakan dalam kegiatan pengabdian ini adalah laptop yang disediakan oleh pelaksana atau smart phone yang langsung dibawa oleh penduduk, LCD proyektor, ruangan, dan stop kontak disediakan oleh pelaksana dan mitra.

\section{HASIL DAN PEMBAHASAN}

Pelaksanaan kegiatan Pengabdian kepada Masyarakat "Sosialisasi penggunaan internet sehat" melibatkan 25 Siswa-siswi di SMK Negeri 1 Marisa, Kabupaten Pohuwato. Uraian pelaksanaan masing-masing sub kegiatan dapat diuraikan sebagai berikut :

\section{Audiensi}

Kegiatan pengabdian ini diawali dengan audiensi yang dihadiri oleh tim pelaksana dan mitra yang diwakili oleh wakil kepala sekolah dan salah satu guru SMK Negeri 1 marisa Kabupaten Pohuwato. Audiensi ini dilakukan pada hari jumat, 13 september 2019 bertempat di ruang kepala sekolah SMK Negeri 1 Marisa. Tujuan diadakannya audiensi ini adalah untuk menjalin hubungan yang baik antara pelaksana pengabdian dan pihak sekolah SMK Negeri 1 Marisa. Dalam kegiatan audiensi ini tim pelaksana TI Poligon menyampaikan seluruh program yang akan dilaksanakan, peranan pelaksana dan mitra dalam kegiatan ini.

\section{Sosialisasi Internet Sehat}

Kegiatan dilaksanakan pada hari Sabtu, tanggal 14 September 2019 pukul 09.00- 12.00 Wita yang dihadiri oleh 25 Siswa-siswi SMK Negeri 1 Marisa Kab. Pohuwato. Kegiatan dilaksanakan di salah satu ruang kelas SMK Negeri 1 Marisa Kabupaten Pohuwato.

Sosialisasi diawali dengan penyampaian materi dari narasumber pertama dengan tema materi "Internet Sehat dan Contoh-contoh Aplikasinya". Setelah itu dilanjutkan oleh nara sumber kedua dengan tema materi, "Internet (penyalagunaan dan dampak hukum". Narasumber banyak mengulas tentang bagaimana menggunakan media sosial secara bijaksana dan pemberian contoh-contoh kasus penggunaan internet yang negatif. Sesi berikutnya adalah sesi tanya jawab antara peserta dan narasumber. Dan terakhir adalah penguatan materi yang disampaikan oleh narasumber ketiga dengan tema materi, "Internet dalam pandangan agama".

\section{Sesi tanya jawab}

Pada kegiatan ini, para siswa-siswi SMK diberikan kesempatan bertanya kepada narasumber mengenai tema yang disampaikan. Adapun pertanyaan yang muncul meliputi bagaimana cara menggunakan media sosial yang baik. Tips menghindari konten-konten negatif. Bagaimana pandangan agama soal internet. Bahkan diskusi berlanjut ke arah pembahasan masalah-masalah remaja di media 
sosial yang terjadi di kabupaten pohuwato dan provinsi gorontalo secara umum. Ada pula yang bertanya tentang persoalan-persoalan teknis serta hal-hal yang berhubungan dengan UU ITE. Selanjutnya diakhir waktu, narasumber memberikan kesimpulan dari hasil diskusi.

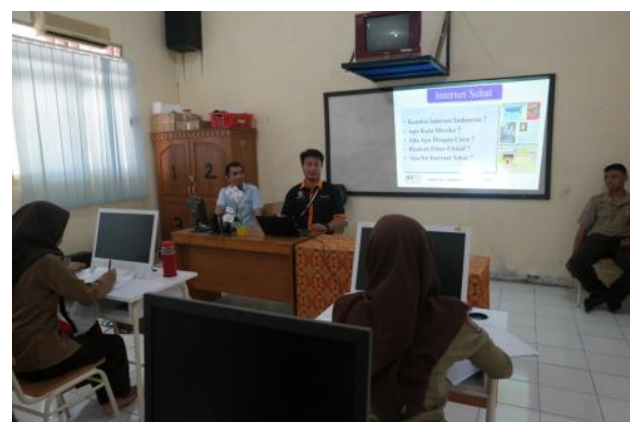

Gambar 2. Materi Internet Sehat

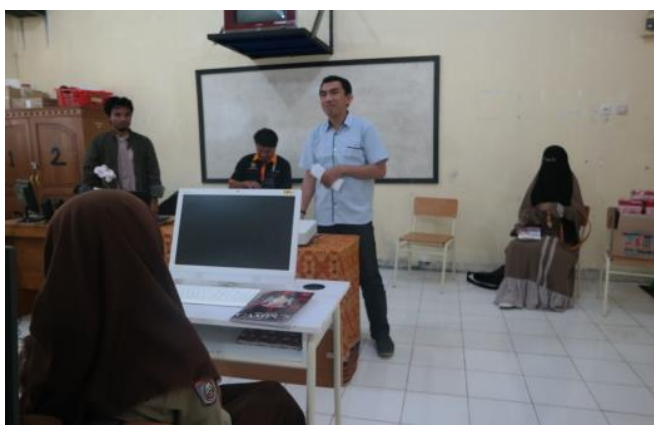

Gambar 3. Materi Penyalahgunaan Internet

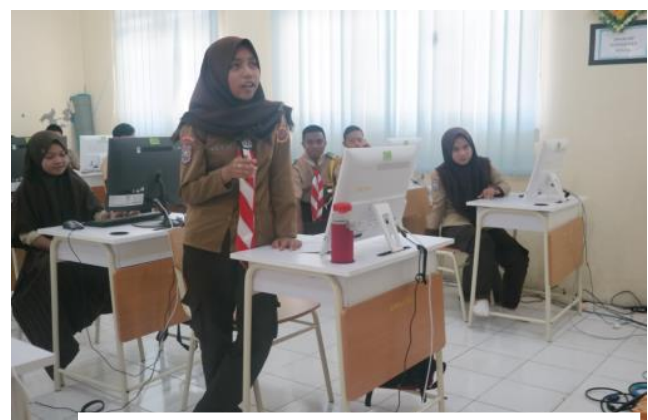

Gambar 4. Sesi Tanya Jawab

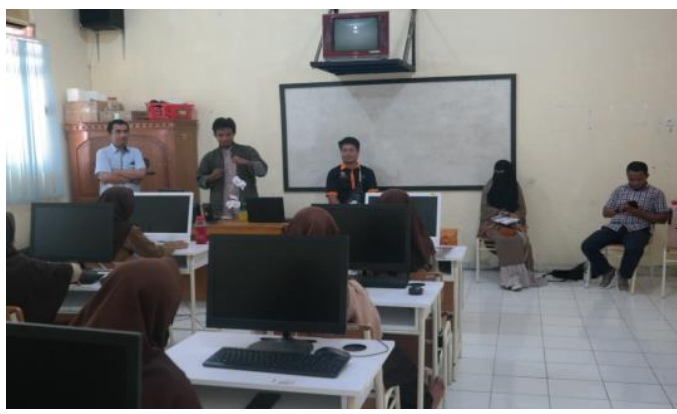

Gambar 5. Internet dalam pandangan Agama
4. Penutup

Kegiatan sosialisasi penggunaan Internet Sehat di SMK Negeri 1 Marisa Kabupaten Pohuwato berakhir pada hari Sabtu, 14 September 2019.

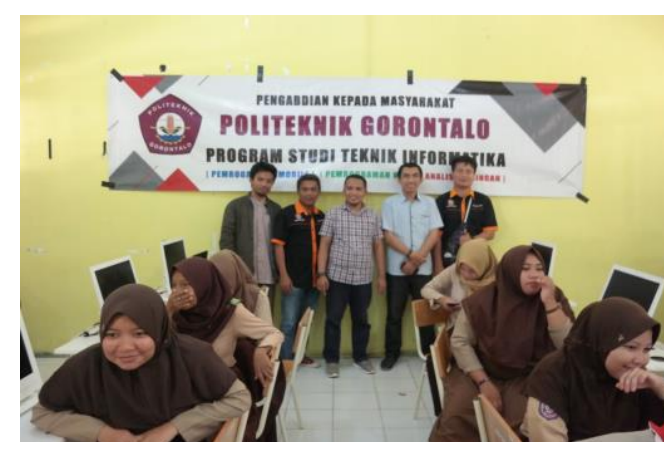

Gambar 6. Foto tim pelaksana dan siswa

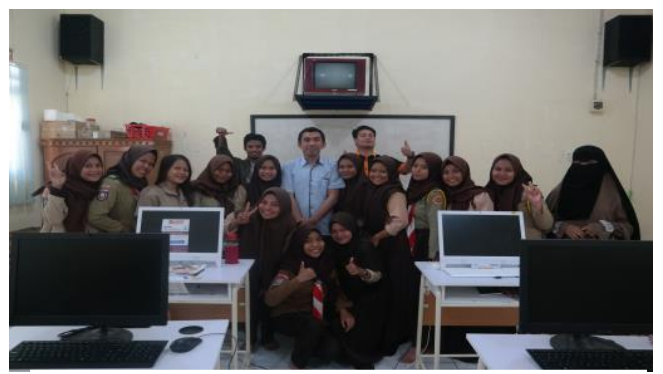

Gambar 7. Foto tim pelaksana dan siswa

\section{KESIMPULAN DAN SARAN}

\section{A. Kesimpulan}

Beberapa hal yang dapat disimpulkan dari hasil kegiatan pengabdian ini diantaranya :

1. Pihak sekolah SMK Negeri 1 Marisa Kabupaten Pohuwato telah menyadari pentingnya upaya untuk terus melakukan kontrol terhadap penggunaan Internet oleh siswa agar mereka menjadi pribadi yang berhasil di masa depan,

2. Pengabdian ini telah meningkatkan pengetahuan ataupun pemahaman siswasiswi SMK Negeri 1 Marisa Kabupaten Pohuwato tentang norma-norma dan dampak yang ditimbulkan dalam menggunakan internet, sehingga para siswa-siswi lebih bijaksana di dalam menggunakan teknologi internet ini. Hal ini nampak dari begitu antusiasnya para siswa dalam sesi diskusi.

3. Terjalinnya kerjasama antara kampus dan sekolah dalam meningkatkan kompetensi lulusan. 


\section{B. Saran}

1. Kepada pihak sekolah, perlu adanya program pendampingan internet sehat di lingkungan SMK Negeri 1 Marisa.

2. Kepada siswa diharapkan mampu menggunakan internet secara optimal dan bijaksana

3. Politeknik Gorontalo khususnya Program Studi Teknik Informatika agar terus melakukan sosialisasi Internet Sehat dikalangan remaja lainnya.

\section{DAFTAR PUSTAKA}

Aprilia, Lina. 2014. Pengaruh Internet Terhadap Akhlak Siswa Kelas XI SMA Negeri 1 Jatisrono, Surakarta : Universitas Muhammadiyah.

Departemen pendidikan Nasional, 2001. Kamus Besar Bahasa Indonesia, edisi ke-3, Jakarta : Balai Pustaka.

Rini Agustina, 2016, Internet Sehat dan Aman (INSAN)

Redaksi, Tim. 2008. Kamus Bahasa Indonesia. Pusat Bahasa Depdiknas.

Iman, Nurul, Katni \& Edi Kurniawan, 2014. Internet Sehat Bagi Santri, M M U A D D I B Vol.04 No.02 Juli-Desember. 